\title{
Le Théâtre de Jean Mairet, sous la direction de Bénédicte Louvat-Molozay, "Littératures classiques", 65
}

Monica Pavesio

\section{(2) OpenEdition}

Journals

\section{Edizione digitale}

URL: http://journals.openedition.org/studifrancesi/7542

DOI: $10.4000 /$ studifrancesi.7542

ISSN: 2421-5856

\section{Editore}

Rosenberg \& Sellier

\section{Edizione cartacea}

Data di pubblicazione: 1 décembre 2009

Paginazione: 616-617

ISSN: 0039-2944

\section{Notizia bibliografica digitale}

Monica Pavesio, «Le Théâtre de Jean Mairet, sous la direction de Bénédicte Louvat-

Molozay, "Littératures classiques", 65», Studi Francesi [Online], 159 (LIII | III) | 2009, online dal 30

novembre 2015, consultato il 09 janvier 2021. URL: http://journals.openedition.org/studifrancesi/7542

; DOI: https://doi.org/10.4000/studifrancesi.7542

Questo documento è stato generato automaticamente il 9 janvier 2021.

\section{cc) (†) $\odot$}

Studi Francesi è distribuita con Licenza Creative Commons Attribuzione - Non commerciale - Non opere derivate 4.0 Internazionale. 


\title{
Le Théâtre de Jean Mairet, sous la direction de Bénédicte Louvat- Molozay, "Littératures classiques", 65
}

\author{
Monica Pavesio
}

\section{NOTIZIA}

Le Théâtre de Jean Mairet, sous la direction de Bénédicte LOUVAT-MOLOZAY, "Littératures classiques", 65, été 2008, pp. 182.

1 Il numero monografico di "Littératures classiques" riunisce undici contributi su Jean Mairet ed il suo teatro, recentemente riedito dall'équipe «Éditions de textes dramatiques du $\mathrm{XVII}^{\mathrm{e}}$ siècle», riunita attorno a Georges Forestier. Collegati a questo progetto editoriale sono i contributi contenuti in questo volume, alcuni dei quali (Vuillermoz, Moncond'huy e Louvat-Molozay) sono nati durante una giornata di studio, tenutasi a Montpellier nel 2004, che ha visto riuniti i curatori del volume sulle tragedie di Mairet. Altri interventi (L. Giavarini- E. Haddad e D. Blocker-E. Haddad) sono il lavoro di una piccola équipe del Groupe de Recherche Interdisciplinaires sur l'Histoire Littéraire (GRILH-Paris III) che studia le attività di scrittura di Mairet come pratiche sociali.

2 Come spiega la direttrice B. LOUVAT-MOLOZAY nella presentazione, Jean Mairet occupa un posto intermedio nel panorama drammatico secentesco: non è un autore maggiore, ma non è neanche un minore. La storia letteraria lo associa a Théophile de Viau ed a Corneille, riconoscendogli il merito di aver fatto da transizione dall'uno all'altro.

3 La prima sezione del volume si apre sulla carriera letteraria di Mairet: A. RIFFAUD illustra il ruolo decisivo di Mairet nella storia del teatro, con le molteplici edizioni delle sue 
opere. L. GIAVARINI e D. BLOCKER, coadiuvate entrambe da E. HADDAD, studiano le êpitres dedicatorie ed indagano sulla rinuncia alla carriera teatrale di Mairet.

4 Segue poi una sezione dedicata alle fonti del teatro di Mairet, da ricercarsi, non tanto nell'Antichità (J.-M. CIVARDI), quanto nell'opera di Honoré d'Urfé (Chr. BARBILLON).

5 L'ultima sezione racchiude cinque articoli consacrati alla pratica dei generi teatrali. Hélène BABY cerca le invarianti della tragicommedia nella Virginie e nell'Illustre Corsaire; M. VUILLERMOZ analizza il trattamento della riconoscenza nelle tragedie; B. LOUVATMOLOZAY dimostra come Mairet nel 1634 con la Sophonisbe e qualche anno dopo con la Sidonie sperimenti un genere alla frontiera della tragedia, la tragicommedia eroica, che non avrà seguito. D. MONCOND'HUY illustra come Mairet, dopo le sue due prime tragedie, ritorni nel Soliman ad una concezione neoumanistica del genere; M. BÉTHERY si occupa dell'Athénaïs, una tragicommedia poco studiata che riprende La Cour Sainte del Père Coussin, svuotandola del suo contenuto religioso.

6 Il contributo di Giovanni ротоLI chiude il volume con i ricordi personali della sua scoperta di Mairet e con la speranza di nuove ricerche sugli elementi euromediterranei presenti nell'opera del drammaturgo e sull'architettura libertina della sua opera. Alcune tabelle sulla fortuna editoriale del teatro di Mairet stilate da A. RIFFAUD concludono il volume. 